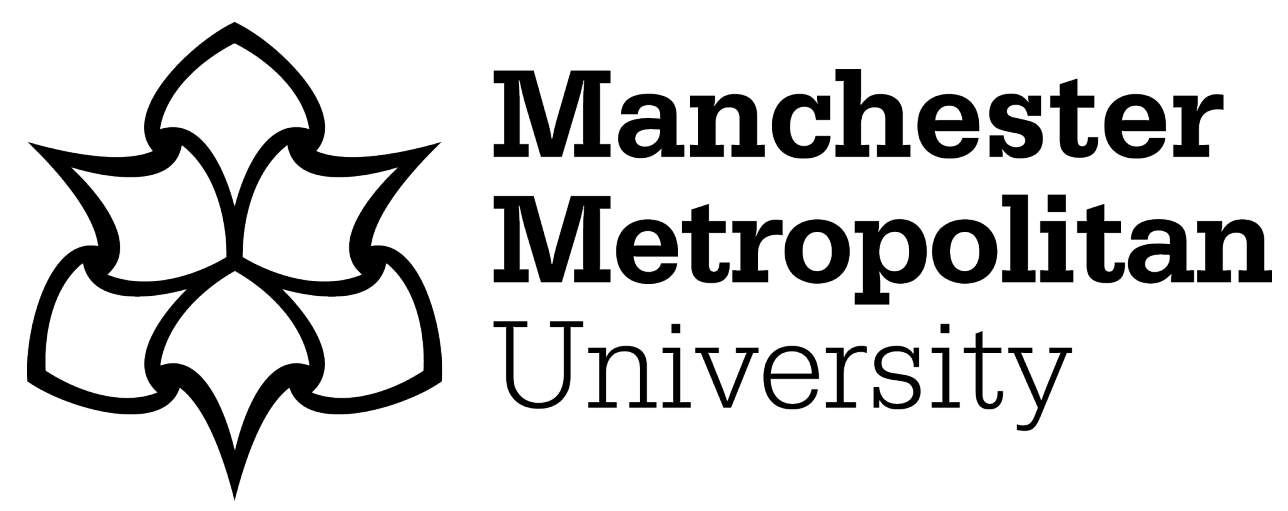

Birch, C, Esfahani, MMN, Shaw, KJ ORCID logoORCID: https://orcid.org/0000-0001-9241-4195, Kemp, C, Haswell, SJ and Dyer, C (2017) The preparation of microfluidic architecture with monolithic materials using a dual porous silica structure. Electrophoresis, 38 (22/23). pp. 2996-3002. ISSN 0173-0835

Downloaded from: https://e-space.mmu.ac.uk/621504/

Version: Accepted Version

Publisher: Wiley

DOI: https://doi.org/10.1002/elps.201700225

Usage rights: Other data licence

Please cite the published version 


\title{
The Preparation of Microfluidic Architecture with Monolithic Materials Using a Dual Porous Silica Structure
}

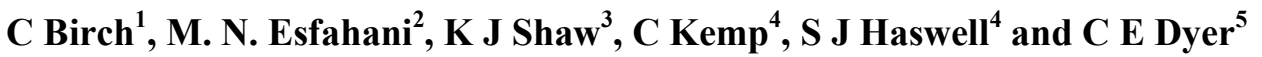

${ }_{1}^{1}$ Department of Chemistry, University of Virginia, McCormick Road, Charlottesville 22903, USA
${ }^{2}$ Orphidia, London, UK
${ }^{3}$ School of Science and the Environment, Manchester Metropolitan University, Chester Street, Manchester, M1 5GD, UK
${ }^{4}$ Deakin University Geelong, Australia
${ }^{5}$ Department of Biological, Biomedical and Environmental Sciences, University of Hull, Cottingham Road, Hull, HU6 7RX, UK

Keywords

Microfluidics, Solid phase extraction, DNA, Porous silica monolith, Urine

\section{List of Abbreviations}

BET Braunner, Emmet, Teller

CCSB Chitosan coated silica beads

DPS Dual porous silica

MD Microfluidic device

MES (N-morpholino) ethanesulfonic acid

PCR Polymerase chain reaction

PS Porous silica

PTFE Polytetrafluoroethylene

SPE Solid phase extraction

TMOS Tetramethyl orthosilicate

\begin{abstract}
A microfluidic device (MD) has been developed which features a porous silica (PS) monolithic disk synthesized from tetramethyl orthosilicate (TMOS), incorporated into the device post-fabrication and sealed in place with a second PS monolithic layer, synthesized from potassium silicate. This dual porous silica (DPS) structure provides a pathway for sample introduction to the microfluidic device and offers an ideal platform for solid phase extraction (SPE) methodologies which can be rapidly and efficiently integrated into a chip-based format. All silica disk manufacture and functionalization was
\end{abstract}

Received: 05 31, 2017; Revised: 07 07, 2017; Accepted: 07 08, 2017

This article has been accepted for publication and undergone full peer review but has not been through the copyediting, typesetting, pagination and proofreading process, which may lead to differences between this version and the Version of Record. Please cite this article as doi: 10.1002/elps.201700225.

This article is protected by copyright. All rights reserved. 
carried out in batch to provide a readily scalable method of production. Application of this design for processing samples was demonstrated using two alternative nucleic acid purification chemistries, yielding polymerase chain reaction (PCR)-amplifiable DNA extracted from $150 \mu \mathrm{L}$ of human urine in less than 35 mins. It is proposed that this DPS system could be further developed for a diverse range of chip-based SPE applications, providing an interface facilitating sample delivery and enabling SPE on-chip. Furthermore, to the author's knowledge it is the first reporting of two different types of porous silica amalgamated in a single microfluidic device.

\section{Introduction}

Over the last twenty years, microfluidic chip-based methodologies have made an increasing contribution in multiple areas, such as clinical diagnostics, forensic analysis, drug detection and various other forms of chemical analysis [1]. Processes of this nature often necessitate the incorporation of a high surface area material for solid phase extraction (SPE) and preconcentration of target analytes. In addition, this material will often serve as an interface between the macro-world and the microfluidic domain [2]. The utilisation of silica chemistries is ubiquitous in the microfluidic literature, due to the hydrophilic nature of silica and it's relatively low cost. Accompanying the first wave of microfluidic devices fabricated from glass, a variety of high surface area silica structures were introduced into microfluidic formats, including silica beads [3] or magnetic silica beads [4], complex channel designs [5] and synthesised porous structures [6]. Groups using bead-based solid phases have often reported lack of reproducibility due to movement of the beads when perturbed by sample and reagents, while those reporting prefabricated high surface area channels comment on lengthy and complicated fabrication protocols. By contrast, those reporting synthesis of porous silica materials or "monoliths" demonstrate rapid and robust synthesis of rigid high surface area structures which can be incorporated into a microfluidic device for a variety of applications [2]. Modes of synthesis also vary, providing the user with sundry properties to select from during both manufacture and usage. For example, porous silica PS synthesis, based on silicon alkoxide precursors such as TMOS, offer an attractive route to establishing a reliable and effective manufacturable real-world to chip interface [7], however shrinkage during the sol-gel process precludes the possibility of in situ production. This led to groups to introduce chemical anchoring techniques or encase the structure in polymer heat shrink wraps [8]. By contrast thermally cured silica monoliths synthesized from the rapid hydrolysis of potassium silicate by formamide are characterised by smaller pores and higher back pressures, but do offer the user the opportunity to cure the structure in situ, as no problematic shrinkage is observed upon gelation [9].

A further advantage of silica-based solid phase processing when used for microfluidic applications is the readiness of silica to be functionalised by alternative functional groups, allowing for a wide range of chemistries to be exploited, particularly in SPE. This is exemplified by the frequent use of silica substrates in DNA extraction methodologies. DNA-silica interactions are dependant on chaotropic salts with dehydrate and reconfigure the DNA structure causing it to be bound to the silica surface via hydrogen bonding. Following a wash with an organic solvent, the system can then be rehydrated and the DNA is released free of contaminants [10]. Several groups have reported high DNA yield from silica-based systems [3][4][5][6][11][12][13]. Amongst alternatives to traditional silica chemistries, anion exchange functional groups have been demonstrated as a recourse to bypass the use of chaotropic salts and organic wash solvents. These processes are driven by simple DNA capture and release mechanisms dependant solely on $\mathrm{pH}$ manipulation. Nakagawa et al. for example implemented a silicon wafer coated with amino groups within a MD, providing DNA recoveries of $40 \%$ from whole blood by binding DNA at $\mathrm{pH} 7.5$ and eluting at $\mathrm{pH} 10.6$ [14]. Chitosan $(\alpha(1 \rightarrow 4)$-linked 2-amino-2-deoxy- $\beta$-D-glucopyranose), a biopolymer consisting of partially deacetylated chitin recovered from crustacean shells, has also been successfully coated on to silica surfaces in a number of formats [15]. Using simple pneumatic pumping, Cao et al. were able to utilise chitosan coated silica beads (CCSB) on a MD that provided DNA extraction efficiencies as high as $75 \%$ from whole blood [16]. More recently, Parton et al. successfully implemented electrokinetic fluid transport to a CCSB system [17] and Reedy et al. demonstrated pre-fabricated polymeric micro-posts treated with chitosan for DNA extraction within microfluidic systems [18]. 
In this technical note, we describe the development of a real-world to chip interface based on a porous silica disk synthesized from a TMOS precursor which has been incorporated into a microfluidic device. Due to the variations in disk diameter associated with shrinkage during manufacture, a second porous silica structure produced from potassium silicate was introduced to provide a robust seal for the disk, while also augmenting the primary structure with its corresponding chemical properties. In addition, to demonstrate the versatility of this dual porous silica (DPS) system afforded by ease of functionalisation, the silica disks were modified with chitosan. In doing so, we show the DPS approach to offer efficient DNA extraction with two alternative chemistries, showcasing the material synthesis and incorporation as a simple and attractive route to manufacturing a reliable real-world to chip interface for SPE.

\section{Materials and methods}

\subsection{Manufacture and preparation of microfluidic device and monolithic materials}

Silica monoliths were synthesized according to the method described by Fletcher et al [8]. Pluronic F127 [Sigma-Aldrich, UK] was dissolved in a $0.02 \mathrm{M}$ acetic acid solution [Sigma-Aldrich, UK]. Once a homogeneous solution had formed, tetramethyl orthosilicate (TMOS) 99\% [Sigma-Aldrich, UK] was added and the solution was stirred for a further 30 minutes under ice bath conditions. Upon formation of a clear solution, the reagents were transferred to $2 \mathrm{~mL}$ plastic syringes, sealed with polytetrafluoroethylene (PTFE) tape and left to dry at $40^{\circ} \mathrm{C}$ for 3 days to allow for gelation. Monoliths were removed from the plastic syringe housing and repeatedly washed in distilled $\mathrm{H}_{2} \mathrm{O}$ until a neutral $\mathrm{pH}$ was obtained. The monoliths were then transferred to a $1 \mathrm{M} \mathrm{NH}_{4} \mathrm{OH}$ solution and heated at $80{ }^{\circ} \mathrm{C}$ under reflux for 24 hours. Finally, monoliths were dried at $40{ }^{\circ} \mathrm{C}$ for 24 hours, then $90{ }^{\circ} \mathrm{C}$ for 8 hours and calcinated in a furnace at $550{ }^{\circ} \mathrm{C}$ for 3 hours to remove any remaining organic residue. Finally, these porous silica rods were cut into disks $2 \mathrm{~mm}$ thick for incorporation into microfluidic devices. The surface area and pore structure was characterised by using nitrogen adsorption/desorption to generate Brauner, Emmett, Teller (BET) isotherms [19].

Microfluidic devices were fabricated from $3 \mathrm{~mm}$ thick borosilicate glass sheets by milling an extraction chamber to a depth of $2 \mathrm{~mm}$ and diameter $7.5 \mathrm{~mm}$ and with drilled exit ports in a top plate before bonding to a bottom plate containing a channel $500 \mu \mathrm{m}$ wide and $100 \mu \mathrm{m}$ deep, produced by photolithography and wet etching (Figure 1)[20]. On insertion of a PS monolithic disk into the extraction chamber cavity, the interface between the monolith perimeter and inner chamber wall was sealed and reinforced with a secondary silica monolithic material, synthesized with a 10:1 solution of potassium silicate $\left(\mathrm{K}_{2} \mathrm{SiO}_{3}\left[21 \% \mathrm{SiO}_{2}, 9 \% \mathrm{~K}_{2} \mathrm{O}\right]\right)$ [VWR International, UK] and formamide [Alfa Aesar, UK] which was then cured at $60{ }^{\circ} \mathrm{C}$. Finally, the extraction chamber was sealed with an 8.5 $\mathrm{mm}^{2}$ glass cover plate with a single drilled central hole into which PTFE tubing was inserted, providing an entry port for sample and reagent delivery onto the device. All samples and reagents delivered via the entry port and flowed through the DPS monolithic disk structure within the extraction chamber and out via the outlet channel beneath to an exit port for removal and collection. Back pressures were measured by a device built in-house, adapted from a gas cylinder regulator [Engweld].

\subsection{Chitosan modification of silica monolith}

Monoliths were coated with chitosan $(\alpha(1 \rightarrow 4)$-linked 2-amino-2-deoxy- $\beta$-D-glucopyranose) [SigmaAldrich, UK], as described by Flores et al [21]. First, chitosan was dissolved to form a $1 \% \mathrm{w} / \mathrm{v}$ solution in $0.2 \mathrm{M}$ acetic acid with shaking and ultrasonication. Silica monolithic disks were immersed in the chitosan solution and heated to $60{ }^{\circ} \mathrm{C}$ in order to lower the viscosity of the chitosan solution and allow easy permeation of the monoliths. After 8 hours, monoliths were removed and washed sequentially with $0.02 \mathrm{M}$ acetic acid and distilled $\mathrm{H}_{2} \mathrm{O}$ three times, both at room temperature and then finally dried for 24 hours at $40{ }^{\circ} \mathrm{C}$.

\subsection{DNA extraction methodologies}

All DNA extraction processes were performed on the microfluidic device using hydrodynamic pumping, allowing sample loading and recovery via entry and exit ports, and flow rates were 
maintained at a constant $10 \mu \mathrm{L} \mathrm{min}^{-1}$. For studies of DNA extraction efficiencies, an artificial urine medium, developed to simulate both composition and $\mathrm{pH}$ of a real urine matrix [22], was spiked with human genomic DNA (hgDNA) $\left(5 \mathrm{ng}^{-1} \mathrm{l}^{-1}\right)$ and mixed at a $1: 9$ ratio with a $5 \mathrm{M} \mathrm{GuHCl}$ in tris/EDTA buffer $\mathrm{pH} 6.7$ solution. $\mathrm{GuHCl}$ is a chaotropic salt which serves as a cell lysis agent and also denatures nucleic acids to drive binding to the silica surface [10]. This total volume $(50 \mu \mathrm{l})$ was then loaded onto the chip allowing binding of nucleic acids to the DPS monolith. $100 \%$ ethanol was then passed through the monolith to wash away contaminants before nucleic acids were eluted with water. A series of $5 \mu \mathrm{l}$ fractions were collected continuously from the outlet channel during the elution stage. The double-stranded DNA (dsDNA) content of all elution fractions was then quantified using a Quant-iT ${ }^{\mathrm{TM}}$ PicoGreen ${ }^{\circledR}$ double stranded DNA Assay Kit [Invitrogen, UK] and analyzed using a FLUOstar Optima Plate Reader [BMG Labtech, UK]. For all experiments DNA extraction efficiency was determined as the total quantity of DNA eluted as a percentage of the quantity of DNA initially loaded onto the system.

To demonstrate the application of this system for the extraction of nucleic acids from high volume, clinically-relevant biological samples, human urine samples were collected from healthy volunteers, having first obtained appropriate ethical approval and donor consent. $\mathrm{GuHCl}(0.072 \mathrm{~g})$ was then added directly to $150 \mu \mathrm{L}$ of human urine in order to achieve a final concentration of $5 \mathrm{M}$, before being loaded onto the DPS monolith disk at $10 \mu \mathrm{L} \mathrm{min}{ }^{-1}$. The subsequent washing and elution steps were performed as previously described.

Initial DNA extraction efficiency experiments performed on chitosan-modified monoliths were carried out using artificial urine, loading the sample in $10 \mathrm{mM}$ 2-(N-morpholino) ethanesulfonic acid (MES) buffer pH 5.05 at a 1:9 ratio, before flushing the monolith with MES buffer pH 5.05 to remove any unbound contaminants. Finally, DNA was eluted using $10 \mathrm{mM}$ tris(hydroxymethyl)aminomethane buffer with $50 \mathrm{mM} \mathrm{KCl} \mathrm{pH} \mathrm{9.} \mathrm{Subsequent} \mathrm{evaluation} \mathrm{of} \mathrm{the}$ system for extraction of DNA from human urine samples was performed by mixing with MES $\mathrm{pH}$ 5.05 at a $1: 9$ ratio and $150 \mu \mathrm{L}$ total volume was loaded on to the monolith at $10 \mu \mathrm{L} \mathrm{min}^{-1}$. Subsequent steps were as previously described.

\subsection{DNA Amplification and Detection Methodology}

Following the various DNA extraction procedures performed on the MD as described, the eluted DNA was subjected to conventional PCR amplification off-chip using a TC-312 thermal cycler [Techne, UK]. The first $5 \mu 1$ of eluted sample was added to a solution of: 2 units GoTaq ${ }^{\circledR}$ DNA polymerase [Promega, UK], GoTaq ${ }^{\circledR}$ buffer, $2 \mathrm{mM} \mathrm{MgCl}_{2}, 10 \mathrm{mg} \mathrm{mL}^{-1}$ bovine serum albumin [NEB Inc., UK], $200 \mu \mathrm{M}$ deoxyribonucleotide triphosphates [Bioline, UK] and $0.1 \mu \mathrm{M}$ each of forward and reverse oligonucleotide primers specific for the amplification of human short tandem repeat locus D21 S11 [23] [Eurofins MWG Operon, Germany]. Samples were then amplified using the following thermal cycling conditions: 2 minute initial denaturation step at $95{ }^{\circ} \mathrm{C}$ followed by 30 seconds at 94 ${ }^{\circ} \mathrm{C}$, 30 seconds at $60{ }^{\circ} \mathrm{C}$ and 30 seconds at $72{ }^{\circ} \mathrm{C}$ for 35 cycles, with a final extension step of 7 minutes at $60^{\circ} \mathrm{C}$.

Amplified DNA samples were analysed by capillary electrophoresis (CE) using a 3500 Genetic Analyzer [Applied Biosystems, UK]. Samples $(1 \mu \mathrm{L})$ were added to $12 \mu \mathrm{L}$ of $\mathrm{Hi}^{\mathrm{D}-\mathrm{Di}}{ }^{\mathrm{TM}}$ Formamide and $0.5 \mu \mathrm{L}$ GeneScan ${ }^{\mathrm{TM}} 500 \mathrm{LIZ}^{\circledR}$ Size Standard [Applied Biosystems, UK]. Prior to CE, samples were denatured at $95^{\circ} \mathrm{C}$, followed by snap-cooling to $4{ }^{\circ} \mathrm{C}$.

\section{Results and discussion}

\subsection{Characterization of DPS system}

Analysis of the pore structure of the TMOS-based monolith used in this work revealed a surface area of $222 \pm 4 \mathrm{~m}^{2} \mathrm{~g}^{-1}$ and a pore volume of $0.9 \pm 0.1 \mathrm{~cm}^{3} \mathrm{~g}^{-1}$, while the potassium silicate-based monolith had a greater surface area of $351 \pm 20 \mathrm{~m}^{2} \mathrm{~g}^{-1}$ and a pore volume of $0.5 \pm 0.1 \mathrm{~cm}^{3} \mathrm{~g}^{-1}$. These structural characteristics were found to be comparable to similar materials reported in the literature [7]. On analysis of images obtained by scanning electron microscopy, the average pore size of potassium silicate-based monoliths and TMOS-based monoliths were shown to be in the region of $1 \mu \mathrm{m}$ to $5 \mu \mathrm{m}$ and $5 \mu \mathrm{m}$ to $40 \mu \mathrm{m}$, respectively (Figure 2). It is postulated that the larger pore size of the TMOSbased monoliths, when compared with the potassium silicate-based monoliths, is responsible for the 
lower surface area, however, it is further postulated that this would offer an increased permeability of the structure for biological samples., It is also important to note that, due to the breadth of study reported previously [7][8] several synthetic means are available by which to modify pore size, should complex samples be probematic for the structures utilised here.

\subsection{Silica-based DNA extraction}

While both monolith types studied display similar porous silica characteristics, notable distinctive features observed were as follows; TMOS-based monoliths could not be synthesized within the chip device due to shrinkage occurring on drying, leading to subsequent leakage of sample from the system, whereas potassium silicate-based monoliths, could be readily cured in situ. Regarding the latter, however, the structural integrity became compromised when synthesized at volumes comparable to that of the TMOS-based monoliths, with the monoliths showing evidence of cracking. For these reasons, this study adopted a novel approach whereby a TMOS-based monolithic disk was synthesised in a batch fabrication process and subsequently inserted post-synthesis into the microfluidic device to provide a primary porous silica structure for SPE methodologies, whilst a second potassium silicate-based layer was coated onto the perimeter of the disk to both seal it in place within the device, whiilst also renforcing the structure chemically. On initial mixing, the potassium silicate solution was of a viscosity suitable for sealing the perimeter of the disk without the porous structure of the disk being penetrated. On curing at $60{ }^{\circ} \mathrm{C}$ this created a seal between the monolithic disk and the microfluidic chamber wall composed entirely of porous silica, producing a dual porous silica (DPS) monolithic structure within the device (Figure 2).

Before carrying out DNA extraction on the DPS system, colored food dye was used to first investigate whether permeation occurs entirely through the monolith, by flowing dye onto the device at $20 \mu \mathrm{L}$ $\min ^{-1}$ and observing the flow pathway. When the PS disk was used alone without a potassium silicate sealing layer then the dye was observed to flow around the outside of the disk showing some fluid was not passing through the main porous silica structure. When the PS disk was used in conjunction with the secondary potassium silicate layer, forming the DPS structure, however, this showed the creation of an efficient seal between the disk and the extraction chamber wall, allowing the dye to fully permeate the internal PS monolith disk structure in its entirety, whilst the perimeter was not breached and no leakage was observed around the edges.

For DNA extraction experiments all samples and reagents were loaded onto the chip and pumped through the monolithic disk vertically via PTFE tubing (see Figure 3 for setup), allowing capture of the analyte on the porous silica surface. Back pressures measured at flow rates of $10 \mu \mathrm{L}$ min-1 were found to be less than 10 psi during the sample loading, wash and elution stages, demonstrating that the porous structure was sufficiently permeable to enable good fluidic penetration whist offering a sufficient back pressure to achieve full distribution across the face of the disk (Table 1). Using artificial urine spiked with hgDNA as a model sample, DNA extraction efficiencies of $44 \pm 3 \%(n=3)$ were achieved. This efficiency was found to be slightly lower $(\approx 10 \%)$ than that reported in the literature, possibly due to small areas of dead volume around the edges of the disk. The chip-based DPS disk system was validated for the extraction of nucleic acids of sufficient quantity and integrity for downstream applications by subjecting the DNA recovered to PCR amplification. In accordance with the literature, it was demonstrated that if there were significant traces of ethanol present in the eluted DNA volume, inhibition of the subsequent PCR resulted [23].

This effect was shown to be prevented by the introduction of an additional of a drying step ( 5 mins) at $40{ }^{\circ} \mathrm{C}$ following the wash step. The drying process permits evaporation of the residual ethanol retained within the PS structure and by adopting this drying step, downstream PCR amplification of extracted DNA was carried out successfully. For the system described here, however, the introduction of a drying step was not desirable, as it increased the time required to complete the process and also necessitated increased user intervention. The biopolymer chitosan was therefore introduced to the DPS to eliminate the drying step by bypassing the ethanol wash step and altering the surface chemistry to that of nucleic acid capture and release by $\mathrm{pH}$ shift. Due to the mode of production, the monoliths were able to be functionalized with chitosan in batch by a simple immersal technique. Importantly, the incorporation and sealing of the chitosan-coated disk within the microfluidic device was carried out at $60^{\circ} \mathrm{C}$, which was not destructive to the chitosan compound. This feature would be very welcome when treating with other organics. 
The performance of the microfluidic chip-based DPS disk system, both with and without chitosan modification, was further evaluated for the extraction of DNA directly from unprocessed human urine samples. Both systems demonstrated efficient processing of a $150 \mu \mathrm{L}$ volume of human urine in MES buffer $\mathrm{pH} 5.05$ (Table 1). Furthermore, the DNA eluted from both systems was subjected to subsequent PCR amplification and the products were analyzed by capillary electrophoresis. In each case the human STR D21 S11 allele was successfully amplified giving products of the expected sizes of 221 and $225 \mathrm{bp}$ [24] indicating that the DNA extracted is of sufficient quantity and integrity for downstream analysis. Figure 4 shows a representative electropherogram of the PCR-amplified D21 S11 allele products obtained with hgDNA extracted from human urine samples using chitosan-coated DPS $(n=3)$. This preliminary study indicates that these microfluidic chip-based DPS systems are potentially compatible for use with clinical samples as the extraction process was not inhibited by urine and yielded DNA suitable for further analysis such as PCR amplification. It is, however, readily acknowledged that further investigation is required to evaluate the performance of the system using clinical samples from a variety of patients, since these can vary greatly in sample composition dependent upon the stage and type of infection occurring. For example, a sample provided by a patient in the advanced stages of an infection could potentially block regions of the porous structures presented here. If this were the case, it may be necessary to modify dimensions of the primary disc structure accordingly, using synthetic strategies described previously [7][8].

\section{Concluding remarks}

The system described here comprises a microfluidic chip-based device for SPE applications, incorporating a novel DPS structure which was demonstrated to provide a real-world to chip sample delivery interface. The silica disk monoliths offer a highly porous structure for easy permeation by samples and reagents, with negligible back pressures, facilitating delivery of samples onto the device. The combination of two different methodologies for synthesising porous silica proved a novel and effective way of incorporating porous materials into a microfluidic device, demonstrating full incorporation of a PS structure into a microfluidic chip with no leakage of sample and reagents during use. To demonstrate SPE capabilities efficient DNA recovery was achieved from $150 \mu \mathrm{L}$ of human urine in less than 35 mins, confirming compatibility of the DPS system with clinically-relevant samples. The high permeability offered by the monolith demonstrates the applicability of the DPS with more complex samples. For example clinical samples from patients where the presence of infection may cause altered sample composition and or water samples with debris present. This may also be the case for water samples retrieved from a natural setting.

The introduction of chitosan to the silica surface, done here to eliminate PCR inhibition by ethanol wash step, exemplified coating/functionalisation of the porous disk. Importantly, the silica disk synthesis and chitosan coating was carried out as a batch preparation prior to incorporation in the microfluidic device which allows for scalable, simple preparation of materials, which is greatly beneficial with respect to considerations for manufacturing and production. Finally, the ability to control the shape and size of the primary porous structure, along with the novel approach to sealing the disk in place, means the system could be employed for a diverse range of SPE applications, including clinical diagnostic, forensic analysis, water analysis and drug detection. 


\section{References}

[1] Whitesides G M, 2006, Nature, 442, 368-73.

[2] Price C W, Leslie D C and Landers J P, 2009, Lab on a Chip, 9, 2484-94.

[3] Wolfe K A, Breadmore M C, Ferrance J P, Power M E, Conroy J F, Norris P M and Landers J P, 2002, Electrophoresis, 23, 727-33.

[4] Berry S M, Alarid E T and Beebe D J, 2011, Lab on a Chip, 11, 1747-53.

[5] Christel L A, Petersen K, McMillan W and Northrup M A, 1999, Journal of Biomechanical Engineering, 121, 22-7.

[6] Shaw K J, Thain L, Docker P T, Dyer C E, Greenman J, Greenway G M and Haswell S J, 2009, Anal Chim Acta, 652, 231-3.

[7] Nakanishi K, 1997, Journal of Porous Materials, 4, 67-112.

[8] Fletcher P I, Haswell S J, He P, Kelly S M and Mansfield A, 2011, Journal of Porous Materials, $18,501-8$.

[9] Qu Q S, He Y Z, Gan W E, Deng N and Lin X Q, 2003, Journal of Chromatography A, 983, 25562.

[10] Melzak K A, Sherwood C S, Turner R F B and Haynes C A, 1996, Journal of Colloid and Interface Science, 181, 635-44.

[11] Kemp C, Birch C, Shaw K J, Nixon G J, Greenman J, Huggett J F, Haswell S F, Foy C A and Dyer C E, 2012, Analytical methods, 4, 2141-44

[12] Baier T, Hansen-Hagge T E, Gransee R, Crombe A, Schmahl S, Paulus C, Drese K S, Keegan H, Martin C, O'Leary J J, Furuberg L, Solli L, Gronn P, Falang I M, Karlgard A, Gulliksen A and Karlsen F, 2009, Lab on a Chip, 9, 3399-405.

[13] Qiu X, Chen D, Liu C, Mauk M, Kientz T and Bau H, 2011, Biomedical Microdevices, 13, 80917.

[14] Nakagawa T, Tanaka T, Niwa D, Osaka T, Takeyama H and Matsunaga T, 2005, Journal of Biotechnology, 116, 105-11.

[15] Dutta P K, Dutta J and Tripathi V S, 2004, Journal of Scientific \& Industrial Research, 63, 20 31.

[16] Cao W, Easley C J, Ferrance J P and Landers J P, 2006, Analytical Chemistry, 78, 7222-8.

[17] Parton J, Birch C, Kemp C, Haswell S J, Pamme N and Shaw K J, 2012, Analytical Methods, 4

[18] Reedy C R, Price C W, Sniegowski J, Ferrance J P, Begley M and Landers J P, 2011, Lab on a Chip - Miniaturisation for Chemistry and Biology, 11, 1603-11.

[19]Sing K S W, 1982, Pure and Applied Chemistry, 54, 2201-18

[20] McCreedy T, 2000, TrAC Trends in Analytical Chemistry, 19, 396-401.

[21] Flores N I H, Ramiraz N F, Valencia, J E, Garcia S R V, Luna-Barcenas G and Garcia-Gonzalez L, 2009, Macromolecular symposia, 283-284, 191-98.

[22] Brooks T and Keevil C W, 1997, Letters in Applied Microbiology, 24, 203-6.

[23] Claveau S, Sasseville M, Beauregard M, 2004, Applied Biosystems. AmpF1STR ${ }_{\circledast}$

[24] SGMPlusTM Kit User Manual, 2008, Nucleic Acids and Cell Biology, 23, 789

\section{Acknowledgements}

The authors would like to thank Steve Clarke for fabrication of the microfluidic devices. The work reported in this paper was supported in part by a PhD scholarship from the University of Hull.

\section{Conflicts of interest}

The authors would like to declare no conflicts of interest.

This article is protected by copyright. All rights reserved. 
Table 1: Evaluation and comparision of the performance of the porous silica SPE systems investigated.

\begin{tabular}{|l|l|l|l|l|}
\hline $\begin{array}{l}\text { PS structure and sample } \\
\text { type }\end{array}$ & $\begin{array}{l}\text { DNA Extraction Efficiency }(\mathrm{n}=3) \\
(\%)\end{array}$ & $\begin{array}{l}\text { Back pressure } \\
(\mathrm{psi})\end{array}$ & $\begin{array}{l}\text { Experimental timescale } \\
\text { (mins) }\end{array}$ & $\begin{array}{l}\text { PCR amplified } \\
\text { DNA }\end{array}$ \\
\hline DPS + artificial urine & $44 \pm 3$ & $<10$ & $<24$ & Yes \\
\hline $\begin{array}{l}\text { DPS-chitosan + artificial } \\
\text { urine }\end{array}$ & $40 \pm 8$ & $<10$ & $<20$ & Yes \\
\hline $\begin{array}{l}\text { DPS + human urine (150 } \\
\mathrm{ml})\end{array}$ & $\mathrm{N} / \mathrm{A}^{\mathrm{a}}$ & $<10$ & $<35$ & Yes \\
\hline
\end{tabular}

${ }^{\text {a }}$ DNA extraction efficiency is not expressed for experiments using human urine samples since these contain host genomic DNA at unknown concentration.

Received: 05 31, 2017; Revised: 07 07, 2017; Accepted: 07 08, 2017

This article has been accepted for publication and undergone full peer review but has not been through the copyediting, typesetting, pagination and proofreading process, which may lead to differences between this version and the Version of Record. Please cite this article as doi: 10.1002/elps.201700225.

This article is protected by copyright. All rights reserved. 


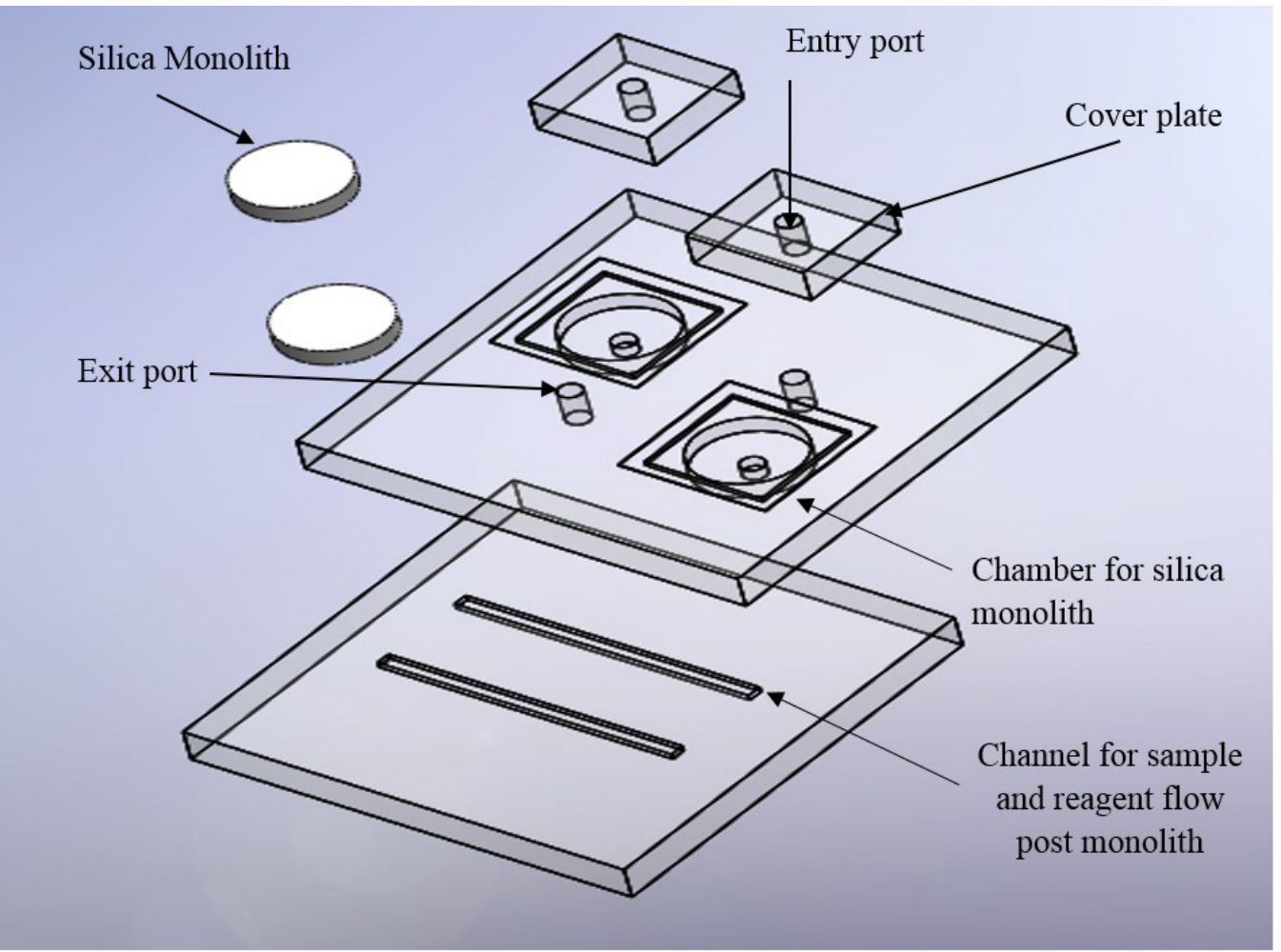

Received: 05 31, 2017; Revised: 07 07, 2017; Accepted: 07 08, 2017

This article has been accepted for publication and undergone full peer review but has not been through the copyediting, typesetting, pagination and proofreading process, which may lead to differences between this version and the Version of Record. Please cite this article as doi: 10.1002/elps.201700225.

This article is protected by copyright. All rights reserved. 


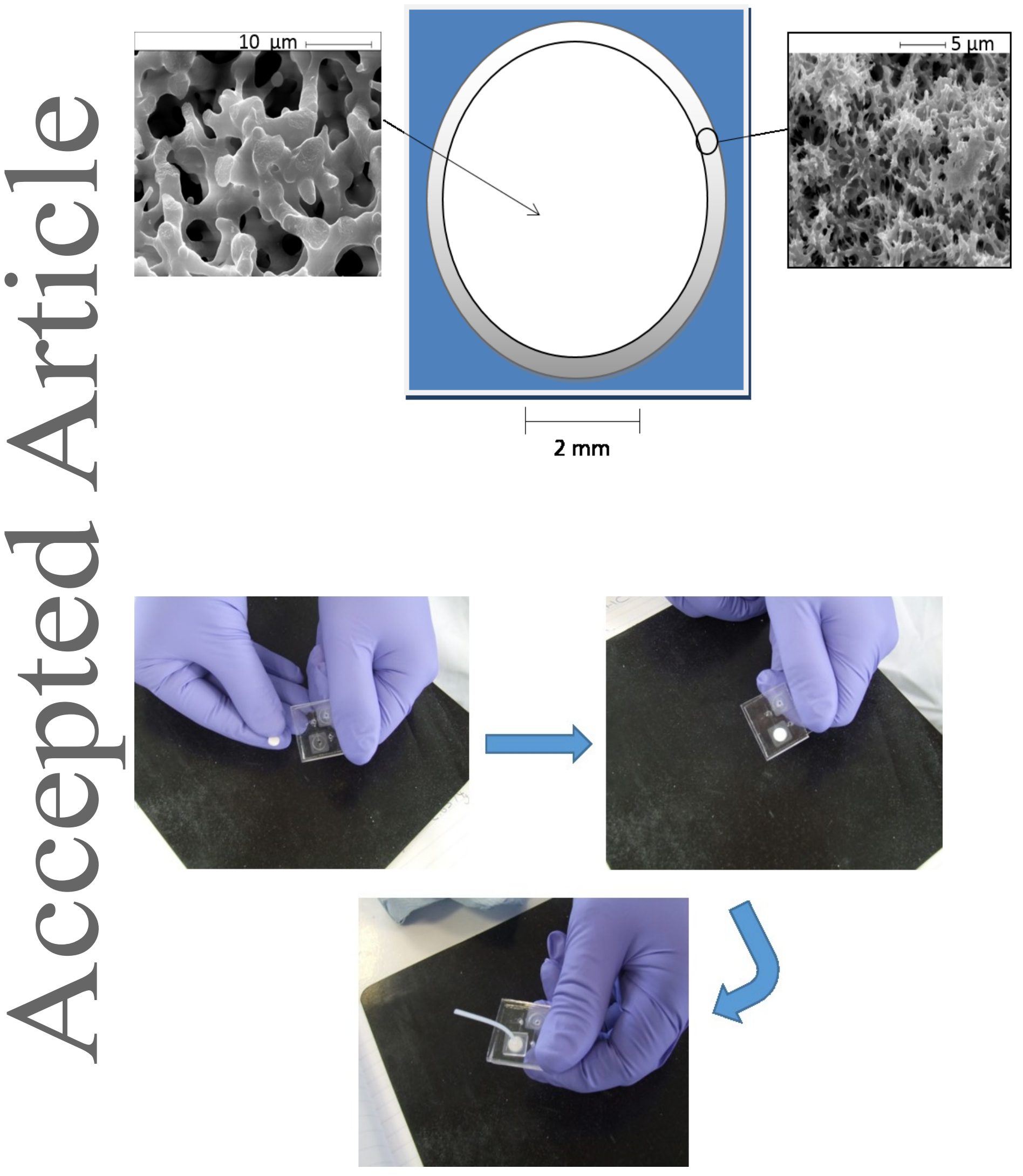

This article is protected by copyright. All rights reserved. 
